\title{
Psychiatry, mental health, mental disability: time for some necessary clarifications
}

\author{
Bruno Falissard $^{1} \cdot$ Marlène Monégat $^{1} \cdot$ Gordon Harper $^{2}$
}

Published online: 18 August 2017

(c) Springer-Verlag GmbH Germany 2017

\section{Introduction}

In most issues of ECAP, we have a wide panorama of papers dealing either with psychiatric disorders [1], disability [2], mental health [3] or subthreshold manifestations [4]. But are we really clear about these different constructs? Good science can be done only with the use of clear and well-defined concepts. Let us see how some of these key notions of the psychiatric and mental health literature are commonly defined and to what extent the situation needs to be clarified.

\section{What is psychiatry?}

According to the website of the American Psychiatric Association, psychiatry is "the branch of medicine focused on the diagnosis, treatment and prevention of mental, emotional and behavioral disorders". This definition is consistent with most of those that are available in other countries, for instance in the dictionary of the French Academy of Medicine, psychiatry is the "medical discipline for the study, prevention, treatment of mental diseases and rehabilitation of patients".

These definitions sound rather natural, even if it is questionable to define a medical specialty in light of diseases treated and not in terms of patients managed. Anyway, as

Bruno Falissard

bruno.falissard@gmail.com

1 CESP INSERM U1018, Université Paris-Saclay, Université Paris-Sud, UVSQ, APHP, Paris, France

2 Department of Psychiatry, Harvard Medical School, Boston, MA, USA the notion of mental disease or disorder seems crucial here, let us take a closer look at this.

\section{What is a mental disease/disorder?}

Even if many papers underline the difficulty of agreeing on a satisfactory definition of disease, there seems to be a beginning consensus about the medical meaning of this term. Indeed, according to Stedman's medical dictionary (US), a disease is a "morbid entity characterized usually by at least two of these criteria: recognized etiologic agent(s), identifiable group of signs and symptoms, consistent anatomic alteration". Similarly, for the dictionary of the French Academy of Medicine, a disease is a "set of abnormal symptoms resulting from the same known cause. Its identification leads to the establishment of a diagnosis and appropriate treatment where it exists".

What is the specificity of a mental disease? Literally, a mental disease affects a patient as being a thinking subject and not a body composed of organs. This dualistic split can be criticized: a patient with a breast cancer is also affected as a thinking subject and a patient with schizophrenia has obviously some trouble with her/his brain. But the experience of having so called mental or somatic disease is so different in practice that the split is commonly accepted, and this occurs in most cultures and has at least since the time of classical Greece.

It is notable that many psychiatrists consider that psychiatric diagnoses lack "etiologic agent". For this reason these diagnoses should be considered more as disorders rather than diseases. This is typical of the feeling of inferiority to their non-psychiatric colleagues that psychiatrists have frequently. Many somatic diseases have unclear etiologies, this is the case for example lymphoblastic acute leukemia 
or psoriasis. On the contrary, we have now solid data that can to a more or less substantial degree explain the occurrence of psychiatric diseases (adverse childhood, genetic vulnerability, neurodevelopmental problems, etc.). Psychiatrists should not abuse euphemisms: mental diseases do exist, just as diseases exist in the rest of medicine.

\section{What is a child and adolescent psychiatric patient?}

As already mentioned, it is surprising to notice that the definition of psychiatry focuses on the treatment of disease and not of patients, who are evidently the core of the physician's attention. Most of the definitions of a patient found in the literature ("a person who suffers", "any recipient of health care services") are not fully satisfying in child and adolescent psychiatry. There is a need here to be creative, in particular to point that, in our field, a community is most often asking for some help instead of a unique individual, as it is classically the case in medicine or even in adult psychiatry. We propose hence the following definition: "A child and adolescent psychiatric patient is a community that calls for help for some suffering in the mind or behavior and locates this suffering in a youth".

Of course, a call for help with suffering is not enough to make a psychiatric patient. There is a threshold below which people do not belong to the field of psychiatry and this is crucial. The definition of this threshold is highly discussed in the literature. Most often, an alteration of functioning is considered to be the key, but why functioning? Is there not a tribute to productivist societies which underestimate the importance of the inner life of human beings? An alternative can be proposed, a more subjective one. The threshold that makes a subject a patient could correspond to a "phenomenological rupture" in the subject's experience or, in some cases, in what people experience with him or her. When we have a bad attack of flu or a depressive episode, we are no more the same human being: we experience a brutal loss of control; life feels different; the specter of death lurks around us. This is the experience of being a patient. In child and adolescent psychiatry, because of the chronic nature of most diseases, this rupture is less obvious. But there is always, at a given moment, a threshold that is crossed and the teacher, the parents, the patient suddenly realize that something problematic is happening.

\section{What are disabilities?}

For a long time, the word disability was used by physicians to name the impairment of a patient induced by the sequelae of an injury or a disease. Since the early 1970 , this approach has been criticized because physicians were playing a role too important in determining what was normal or not for a human life. An alternative has been progressively proposed, challenging the level of adequacy between a subject and the society in which this subject lives. This is obviously the option that WHO followed in its International Classification of Functioning, Disability and Health (ICF), published in 2001. For WHO, disability is "an umbrella term, covering impairments, activity limitations, and participation restrictions. [...] Disability is thus not just a health problem. It is a complex phenomenon, reflecting the interaction between features of a person's body and features of the society in which he or she lives".

Disabilities are related to impairments of different kinds, classically they can be "cognitive, developmental, intellectual, mental, physical, sensory, etc." Obviously, child and adolescent psychiatry is involved in many of these domains and the question of the border between health care and disability management becomes a day-to-day issue, in particular because funding dedicated to the first in general impacts on that of the second and vice versa. But the raison d'être of health care and disability management are fundamentally different: health care responds to the call of a suffering subject while disability management repairs the injustice of being inadequate within a society.

\section{What is mental health?}

WHO proposed in 2001 the following definition of mental health: "mental health is a state of well-being in which the individual realizes his or her own abilities, can cope with the normal stresses of life, can work productively and fruitfully, and is able to make a contribution to his or her community".

Obviously, mental health goes far beyond psychiatry. Mental health encompasses the promotion of well-being, the prevention of mental suffering and mental disorders, the treatment of mental disorders and the management of disability. Then what is the common point between all these entities? It is not the patient but rather the citizen. It is considered here that every citizen, with or without psychiatric disorders, has the right to mental health during his or her life course.

Then psychiatry, as the discipline that prevents and treats mental diseases, appears as an integral part in the promotion of mental health. Considering a psychiatric patient as a citizen like any other can contribute among others to destigmatize psychiatry. Opening psychiatry to other horizons can contribute to develop one of its neglected missions: prevention.

But psychiatry is still an entity on its own rights, within mental health. One important issue in integrating psychiatry into mental health-for the discipline of psychiatry as 
well as for the individuals-is to determine the threshold above which an individual who suffers should be evaluated and treated by a psychiatrist. And we come back here to the notion of rupture as introduced above.

Finally, if dealing with mental suffering or mental disorders is a condition to reach well-being, well-being is, for a long list of philosophers, much more than an absence of suffering. This has a practical consequence that child and adolescent psychiatrists often forget: our role is not to make children and adolescents happy. Our role is more modest, but at the same time so important: dealing with suffering, the very necessary condition of a possibility to engage in a human existence.

\section{The particular situation of child and adolescent psychiatry: how history explains the complexity of its situation}

Child and adolescent psychiatry has been closely linked with non-medical fields since its beginnings. In France, educationalists were the first interested in studying children. Then in 1800 , Itard proposed the first medico-educational therapy. In the US, social workers and others called attention to children in the criminal justice system leading to the creation of the Juvenile Psychopathic Institute under William Healy, in 1899. Today, there are still close relationships between child and adolescent psychiatry and education or the judiciary system. From a mental health perspective, school appears as a relevant place to implement actions to prevent mental suffering. Obviously, it seems necessary that child and adolescent psychiatrists take into account the educational or judicial difficulties potentially associated with mental troubles. However, we should keep in mind that the child and adolescent psychiatrist's mission is not to improve pupils' performance or even to prevent delinquency.

Today, child and adolescent psychiatry is not recognized everywhere as an independent medical specialty. A prerequisite is to recognize childhood and adolescence as distinct developmental periods, which is not the case in every society. Another condition is that child and adolescent psychiatry is different from pediatrics and adult psychiatry. But the relationships between these specialties have been complex since a very long time. For example, in the UK, Aubrey Lewis (1900-1975) advocated the independence of child psychiatry whereas Donald Winnicott (1896-1971) advocated training of pediatricians as child psychiatrists. The situation is still heterogeneous today. In some countries, child and adolescent psychiatry is a subspecialty of adult psychiatry whereas in others it is an independent discipline. The issue of the relationships between these disciplines is not important only in a professional or epistemological way. It also raises important issues concerning patient's care such as the transition between child and adult care or the articulation between somatic and psychiatric care.

Furthermore, child and adolescent psychiatry has been subjected to inner tensions between different perspectives throughout its history. Psychoanalysis was predominant a few decades ago. It is now substituted by a perspective rooted in biology and neurosciences, convening a different conception of the individual and different diagnosis and therapeutic approaches. Today these two perspectives are systematically opposed. But given the complexity of the issue and the lack of knowledge, questions arise: can we really reject one approach in favor of the other? Rather than pointing out the differences, can't we try to make these two perspectives collaborate? Beyond helping to produce knew knowledge, this could allow us to choose between different psychotherapeutic approaches and to identify the one most suitable for an individual patient.

\section{Psychiatry, mental health, disability: different worlds obliged to work together}

Psychiatry deals with subjects who suffer so much because of their mind or their behaviors that they feel the necessity to meet a professional. Disability focusses on the necessity to repair the injustice of being inadequate within a society. Mental health goes far beyond psychiatry and disability; well-being and perhaps self-actualization seem to be the keywords here.

We are confronted with three systems that are epistemologically different, but real life does not rely only on epistemological considerations. In practical terms, the best way to prevent mental disorders is by improving well-being in youths. Indeed, early parenting support can prevent childhood adversity, a major risk factor for many mental disorders. It can also improve autonomy and selfesteem in children and adolescents; two essential components of well-being and mental health.

In addition, many clinical situations in child and adolescent psychiatry imply the integrative work among others, parents, teachers, social workers, judges, psychologists, and psychiatrists. In such a context it is difficult to disentangle what is related to the patient who suffers or to the young citizen that has to be supported. Psychiatry, mental health, and disability management often look like the strands of a braid: they do exist independently but they are really relevant only when they are considered together. 


\section{References}

1. Nagl M, Jacobi C, Paul M, Beesdo-Baum K, Höfler M, Lieb R, Wittchen H-U (2016) Prevalence, incidence, and natural course of anorexia and bulimia nervosa among adolescents and young adults. Eur Child Adolesc Psychiatry 25(8):903-918. doi:10.1007/s00787-015-0808-z

2. Leonard H, Foley K-R, Pikora T, Bourke J, Wong K, McPherson L, Lennox N, Downs J (2016) Transition to adulthood for young people with intellectual disability: the experiences of their families. Eur Child Adolesc Psychiatry 25(12):1369-1381. doi:10.1007/s00787-016-0853-2
3. Sharpe H, Patalay P, Fink E, Vostanis P, Deighton J, Wolpert M (2016) Exploring the relationship between quality of life and mental health problems in children: implications for measurement and practice. Eur Child Adolesc Psychiatry 25(6):659-667. doi:10.1007/s00787-015-0774-5

4. Dickstein DP, Axelson D, Weissman AB, Yen S, Hunt JI, Goldstein BI, Goldstein TR, Liao F, Gill MK, Hower H, Frazier TW, Diler RS, Youngstrom EA, Fristad MA, Arnold LE, Findling RL, Horwitz SM, Kowatch RA, Ryan ND, Strober M, Birmaher B, Keller MB (2016) Cognitive flexibility and performance in children and adolescents with threshold and sub-threshold bipolar disorder. Eur Child Adolesc Psychiatry 25(6):625-638. doi:10.1007/s00787-015-0769-2 